\title{
Wear Resistance Performance of Conventional and Non-Conventional Wind Turbine Blades with TiN Nano-Coating
}

\author{
Muhammad Hasibul Hasan and Shugata Ahmed
}

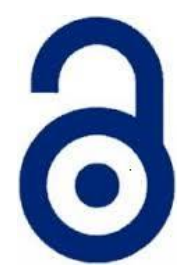

\author{
Received: 13 April 2017 \\ Accepted: 08 July 2017 \\ Published: 15 September 2017 \\ Publisher: Deer Hill Publications \\ (C) 2017 The Author(s) \\ Creative Commons: CC BY 4.0
}

\begin{abstract}
Efficiency and durability are critical issues that affect widely-adopted aerofoil-power generator as a sustainable source of electrical power. Even though high wind power density can be achieved; installing wind turbines in desert condition has difficulties including thermal variation, high turbulence and sand storms. Sand blasting on turbine blade surface at high velocities causes erosion resulting turbine efficiency drop. Damage-induced erosion phenomena and aeroelastic performance of the blades needed to be investigated. Suitable coating may prevent erosion to a great extent. A numerical investigation of erosion on NACA 4412 wind turbine blade has been performed using commercial computational fluid dynamics software ANSYS FLUENT 14.5 release. Discrete phase model (DPM) has been used for modelling multi-phase flow of air and sand particles over the turbine blade. Governing equations have been solved by finite volume method (FVM). Conventional 30-70\% glass fibre resin and non-conventional jute fibre composite have been used as turbine blade material. Sand particles of $0.3 \mathrm{~mm}$ diameter have been injected from $20^{\circ}, 30^{\circ}, 45^{\circ}$, $60^{\circ}$ and $90^{\circ}$ angles at $50^{\circ} \mathrm{C}$ temperature. Erosion rate, wall shear stress and strain rate have been calculated for different wind velocities and impingement angles. Simulation results for higher velocities deviate from the results observed at lower wind velocities. In simulation, erosion rate is highest for $30^{\circ}$ impingement angle at low wind velocities, which has been validated by experiment with a mean absolute error (MAE) of 5.56\%. Erosion rate and wall shear stress are higher on jute composite fibre than glass fibre resin. Developed shear stress on wind turbine blade surface is highest for $20^{\circ}$ impingement angle at all velocities. On the other hand, exerted pressure on turbine blade surface is found highest for $90^{\circ}$ angle of attack. Experimental results, with or without Titanium nitride(TiN) nano-coating, also revealed that surface roughness augments with increasing impingement angles. Nano-coating (TiN) by RF sputtering technique reduced the surface roughness significantly as oppose to uncoated samples. Highest roughness has been observed on uncoated blade surface collided with 0.3-0.69 mm diameter brown aluminium oxide particles.
\end{abstract}

Keywords. Turbine blade, Aerofoil, Nano coating, Wear, Wear resistance, Power generation, Turbine efficiency, Fibre composite turbine blade

\section{INTRODUCTION}

Combustion of bio-fuels generates greenhouse gases. Releasing greenhouse gases is one of the major reasons of atmospheric temperature rise. Moreover, amount of underground petroleum storage is limited. Hence, renewable energy, such as wind, solar, geothermal etc., is becoming popular day by day as alternative sources. Wind energy is clean, available and easy to convert to electrical energy. Wind turbines are used to generate electrical power from wind energy. However, selecting turbine blade material is a critical issue. Moreover, in desert condition air flows with sand particles at relatively high velocities. Sand blasting on turbine blade surface results significant erosion. Hence, a sharp decrement of turbine efficiency is observed with time.

\section{H. Hasan $区$}

Department of Mechanical and Industrial Engineering

Ryerson University, Canada

E-mail: hasibulhasan@ryerson.ca

\section{S. Ahmed}

Department of Robotics and Mechatronics Engineering

Kazi Motahar Hossain Bhaban

University of Dhaka, Dhaka 1000, Bangladesh

E-mail: shugataahmed.rme@du.ac.bd

Reference: Hasan, M. H., and Ahmed, S. (2017). Wear Resistance Performance of Conventional and Non-Conventional Wind Turbine Blades with TiN Nano-Coating. International Journal of Engineering Materials and Manufacture, 2(3), 37-47. 


\section{Nomenclature}

\begin{tabular}{|cl|}
\hline$a$ & Particle impact angle $\left(^{\circ}\right)$ \\
$A_{\text {face }}$ & Surface area of impacted wall boundary cell $\left(\mathrm{mm}^{2}\right)$ \\
$d_{p}$ & Particle diameter $(\mathrm{mm})$ \\
$\vec{g}$ & Gravitational acceleration $\left(\mathrm{ms}^{-2}\right)$ \\
$k$ & Turbulence kinetic energy $\left(\mathrm{m}^{2} \mathrm{~s}^{-2}\right)$ \\
$\dot{m}_{p}$ & Particle mass flow rate $\left(\mathrm{kgs}^{-1}\right)$ \\
$n$ & Material independent index \\
$P$ & Pressure $(\mathrm{Pa})$ \\
$R e$ & Reynolds number \\
$R_{\text {erosion }}$ & Erosion rate $\left(\mathrm{kgm}^{-2} \mathrm{~s}^{-1}\right)$ \\
$T$ & Temperature $\left({ }^{\circ} \mathrm{C}\right)$ \\
$\vec{u}$ & Velocity of air $\left(\mathrm{ms}^{-1}\right)$ \\
$\vec{u}_{p}$ & Particle velocity $\left(\mathrm{ms}^{-1}\right)$ \\
$v_{i}$ & Particle impact velocity $\left(\mathrm{ms}^{-1}\right)$ \\
$\alpha$ & Volume fraction of air \\
$\epsilon$ & Turbulence kinetic energy dissipation rate $\left(\mathrm{m}^{2} \mathrm{~s}^{-3}\right)$ \\
$\theta$ & Solid domain temperature $\left({ }^{\circ} \mathrm{C}\right)$ \\
$\mu$ & Dynamic viscosity $\left(\mathrm{N} . ~_{\mathrm{sm}}{ }^{-2}\right)$ \\
$\rho$ & Density of air $\left(\mathrm{kgm}^{-3}\right)$ \\
$\rho_{p}$ & Particle density $\left(\mathrm{kgm}^{-3}\right)$ \\
\hline
\end{tabular}

Numerous trials for selecting proper wind turbine blade materials have been remarked in the literature. Mishnaevsky et al. [1] studied the usability of timber as a turbine blade material. Their investigation represents a framework for fabrication, testing and installation of timber blades. Composite materials are also getting attentions for fabricating wind turbine blades due to their low cost and attractive properties. Polymer composites had been considered by researchers to enhance surface resistance to wear such as carbon fibres, short aramids or glass [2-7], polyetheretherketone (PEEK) [8], polyphenylene sulfide (PPS) [9], polyoxymethylene (POM) [10], polyamide (PA) [11] etc.

Patnaik et al. [12] numerically and experimentally investigated erosion rate on zinc-aluminum alloy metal (ZA27) filled with titania $\left(\mathrm{TiO}_{2}\right)$ for different particle impact velocity, size, temperature and impingement angle. They observed that highest erosion rate occurs at $60^{\circ}$ impingement angle. Erosion rate on unfilled base metal was found higher than reinforced alloy. Erosion on composite material was also investigated experimentally by Drensky et al. [13]. It was found that mass loss of the material is highest for $45^{\circ}$ impact angle. Wind velocity, particle size and fibre orientation also have great influence on mass loss. Simulation was carried out by Fiore et al. [14] to investigate erosion on wind turbine blade for insects and sand particles impact. Maximum erosion rate was detected on blade's low pressure side. Wind tunnel testing was conducted by Gaudern et al. [15] to figure out erosion patterns on wind turbine blade surface under varying conditions. Hamed et al. [16] also explored surface damage of turbine blade both numerically and experimentally. Their results show that erosion and surface roughness enhance with increasing impact angle and particle size. Foley et al. [17] studied erosion behaviour of steel AISI 4340 and found that for the same material hardness, the erosion at impact angle of $30^{\circ}$ was much greater than at $90^{\circ}$. On the other hand, Hutchings [18] reported erosion peaks at $90^{\circ}$ for AISI 52100 steel. E. Rodríguez et al. [19] found three different wear regions based on impact angles and hardness. Higher amount of wear found for $10^{\circ}$ and $20^{\circ}$ impact angles at lower hardness value, while, for impact angles of $60^{\circ}, 75^{\circ}$ and $90^{\circ}$, amount of wear is high for higher hardness value. For impact angles of $30^{\circ}$ and $40^{\circ}$, wear is almost same for all hardness values.

An effective way to prevent erosion on wind turbine blade is to provide coating. Rico et al. [20] accomplished low wear on SAE-42 steel by depositing $\mathrm{Al}_{2} \mathrm{O}_{3}-13 \% \mathrm{TiO}_{2}$ coating. Liang et al. [21] substantially improved damping properties of wind turbine blade using carbon nanofibre nanocomposite coating. Nano/polymer coating is promising for preventing erosion to a great extent. Zhang et al. [22] tested silica filled transparent acrylate-based coatings and remarked that nanosilica particles improve erosion resistance properties. Figure 1 illustrates coating with different percentage of nanosilica particles.

In this paper, a static NACA 4412 single wind turbine blade under desert condition has been simulated by software and laboratory setup. Numerical investigation has been carried out by ANSYS FLUENT 14.5 release. In software, discrete phase model (DPM) has been used to simulate the multiphase flow of air and sand particles. Erosion rate, development of shear stress and strain on wind turbine blade surface have been investigated. Aerodynamic performances of turbine blade have also been explored. Experiment has been carried out using air jet erosion tester. Simulation results show good agreement with experimental data. 

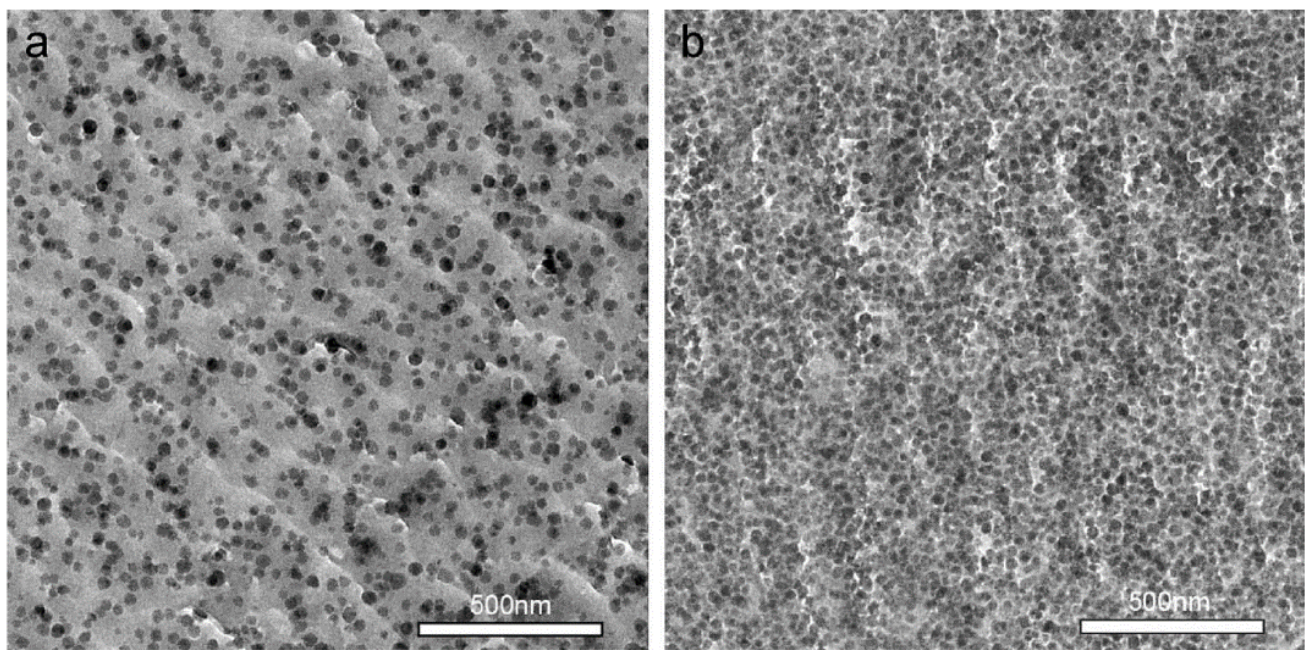

Figure 1: TEM micrograph of nano/polymer coating with (a) $10 \mathrm{wt} \%$ and (b) $40 \mathrm{wt} \%$ nanosilica particles [22].

\section{MATHEMATICAL MODEL}

Discrete phase model (DPM) has been used to simulate the flow of air and sand particles. In DPM, the fluid phase is considered as continuum and solid particles are treated as discrete phase. Discrete solid particles are tracked in the flow field in a Lagrangian frame of reference, where governing equations are solved for a single particle. On the other hand, transport equations for per unit volume of continuum phase is derived, which is Eulerian approach for modelling multiphase flow. The force balance equation for a single sand particle is following:

$$
\frac{d u_{p}}{d t}=F_{D}\left(\vec{u}-\vec{u}_{p}\right)+\frac{\vec{g}\left(\rho_{p}-\rho\right)}{\rho_{p}}+\vec{F}
$$

As sand particles are very small, it is considered that no gravitational force is acting on them. Hence, gravitational acceleration $\vec{g}=0$. The term $F_{D}\left(\vec{u}-\vec{u}_{p}\right)$ defines the drag force/ unit mass of sand particle where

$$
F_{D}=\frac{18 \mu C_{D} R e}{\rho_{p} d_{p}^{2} 24}
$$

Relative Reynolds number is defined as

$$
R e=\frac{\rho d_{p}\left|\vec{u}_{p}-\vec{u}\right|}{\mu}
$$

The governing equations for air is derived by Eulerian method. Continuity equation is the following:

$$
\frac{\partial(\alpha \rho)}{\partial t}+\nabla(\alpha \rho \vec{u})=0
$$

Conservation of momentum equation:

$$
\frac{\partial(\alpha \rho \vec{u})}{\partial t}+\nabla(\alpha \rho \vec{u} \vec{u})=-\alpha \nabla P+\nabla \tau
$$

Standard $k-\varepsilon$ turbulence model [12] is used for turbulence flow modelling. Equations related to turbulence:

$$
\begin{aligned}
& \frac{\partial(\rho k)}{\partial t}+\nabla(\rho k u)=\nabla\left(\alpha_{k} \mu_{e f f} \nabla k\right)+G_{k}+G_{b}-\rho \varepsilon-Y_{M}+S_{k} \\
& \frac{\partial(\rho \varepsilon)}{\partial t}+\nabla(\rho \varepsilon u)=\nabla\left(\alpha_{\varepsilon} \mu_{e f f} \nabla k\right)+C_{1 \varepsilon} \frac{\varepsilon}{k}\left(G_{k}+C_{3 \varepsilon} G_{b}\right)-C_{2 \varepsilon} \rho \frac{\varepsilon^{2}}{k}-R \varepsilon+S_{\varepsilon}
\end{aligned}
$$

In equation (6) and (7)

$G_{k}=$ Generation of turbulence kinetic energy due to the mean velocity gradients

$G_{b}=$ Generation of turbulence kinetic energy due to buoyancy

$Y_{M}=$ Contribution of the fluctuating dilatation in compressible turbulence to the overall dissipation rate

$S_{k}=$ Source term for turbulence kinetic energy

$S_{\varepsilon}=$ Source term for turbulence kinetic energy dissipation rate

The erosion model is included in DPM. Erosion rate is defined by following equation:

$$
R_{\text {erosion }}=\sum_{p=1}^{N_{\text {particles }}} \frac{\dot{m}_{p} c\left(d_{p}\right) F(a) v_{i}^{n}}{A_{\text {face }}}
$$


Here, $C\left(d_{p}\right)$ is particle diameter function and $F(a)$ is impact angle function. Following boundary conditions are applied in the computational domain to solve the governing equations numerically:

Inlet: velocity of air at $\mathrm{Y}$-direction, $u_{y}=u_{i n}$; other velocity components, $u_{x}=u_{z}=0$; temperature of air and sand particles, $T_{i n}=50^{\circ} \mathrm{C}$; mass flow rate of sand particles, $\dot{m}=\dot{m}_{\text {in }}$.

Outlet: pressure, $p=p_{\text {out }}$. Atmospheric pressure is defined at domain outlet.

Walls: Fluid velocity adjacent to stationary domain walls, $u=0$.

Outer walls are considered thermally insulated. Hence, temperature gradient normal to the wall, $\frac{\partial \theta}{\partial n}=0$.

\section{NUMERICAL SIMULATION}

\subsection{Meshing and Grid Independent Test}

A Hybrid mesh has been generated by ANSYS Workbench. Figure 2 shows meshing of turbine blade surface and the fluid domain with $60^{\circ}$ impingement angle. The grid consists of hexahedron elements. Minimum number of elements should be considered in the simulation to minimize computational time. To find out optimum number of elements, grid independent test has been carried out. Erosion rate has been observed for $1.3 \times 10^{5}$ to $1.5 \times 10^{5}$ number of elements and relative error has been calculated, which are shown in Table 1. Finally, 144828 number of cells has been selected for simulation with a relative error of $1.36 \%$.

\subsection{Solution methods}

Governing equations have been solved numerically by finite volume method (FVM). Second order upwind scheme has been used for discretization. Pressure-velocity coupling equation has been solved by Semi-Implicit Method for Pressure Linked Equations (SIMPLE) algorithm, developed by Patankar and Spalding [13].

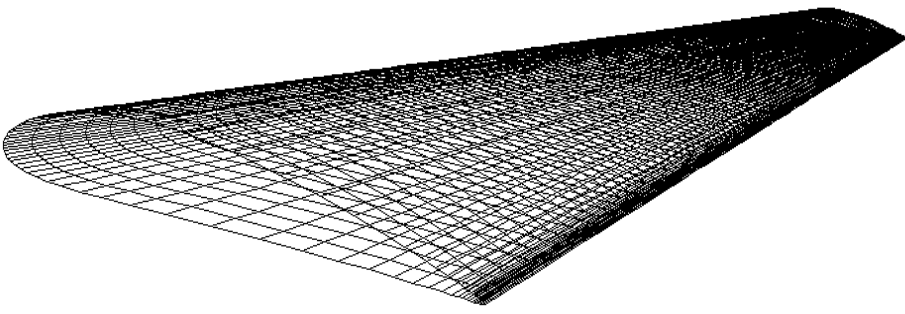

(a)

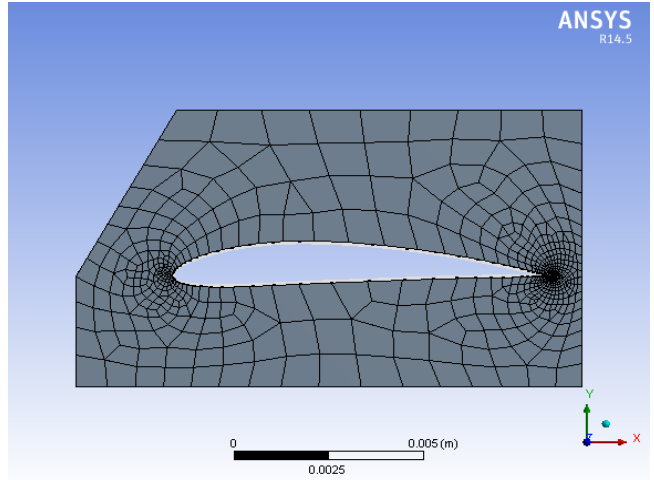

(b)

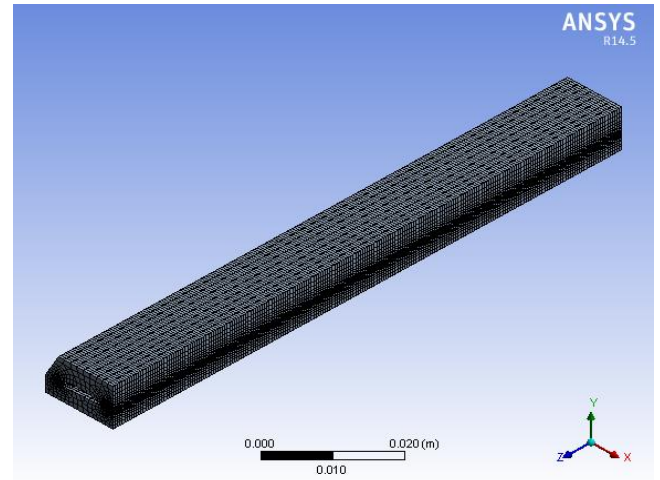

(c)

Figure 2: (a) Wind turbine blade surface meshing; Meshing of fluid domain with $60^{\circ}$ impingement angle (b) crosssectional view, (c) three dimensional view.

Table 1: Grid independence test results

\begin{tabular}{ccc}
\hline No. of elements & $\mathrm{R}_{\text {errosion }}\left(\mathrm{kg} \cdot \mathrm{m}^{-2} . \mathrm{s}\right)$ & Relative error (\%) \\
\hline 134425 & $1.31 \times 10^{-7}$ & 13.74 \\
137854 & $1.38 \times 10^{-7}$ & 7.97 \\
144828 & $1.47 \times 10^{-7}$ & 1.36 \\
148710 & $1.44 \times 10^{-7}$ & 3.47 \\
153318 & $1.49 \times 10^{-7}$ & -- \\
\hline
\end{tabular}




\section{EXPERIMENTAL STUDY}

\subsection{Samples and nanocoating}

Glass fibre $6 \times 2 \mathrm{~cm}$ samples were collected from the $3 \mathrm{~mm}$ thick turbine blades and jute reinforced epoxy resin composite samples were prepared in the laboratory. Multiple acetone wash removed dusts and gel coat of the turbine blades, if any. RF sputtering technique was adopted for the coating while target material was $99.99 \%$ Titanium. Gas flow rate for Argon (Ar) was $50 \mathrm{sccm}$ and for Nitrogen (N) was $5 \mathrm{sccm}$. Duration of each deposition was 60 minutes.

\subsection{Sand blasting and roughness analysis}

Sand blasting machine with a blasting pressure of 50 psi $(20 \mathrm{~m} / \mathrm{sec})$ and 75 psi $(35 \mathrm{~m} / \mathrm{sec})$ were used to erosion rate calculation. The test rig is shown in Figure 3. Target samples were kept $20 \mathrm{~cm}$ away from the nozzle tip and the duration of sand blasting was 10 seconds for each sample. Brown aluminium oxide of 0.30 to $0.70 \mathrm{~mm}$ particles were used as sand particles. Sand blasted samples were analysed by Mitutoyo Surftest (SJ-301) surface roughness analyser. JIS B0601(2001) method was adopted and Gauss filter was used to calculate the roughness (Ra) value.

\section{RESULTS AND DISCUSSION \\ 5.1 Simulation results \\ 5.1.1 Erosion rate}

Figure 4 shows the contour plot of erosion on wind turbine blade surface of glass fibre resin for $60 \mathrm{~ms}^{-1}$ wind velocity and $90^{\circ}$ impingement angle. It is observed that highest erosion rate on turbine blade surface is $1.4 \times$ $10^{-6} \mathrm{kgm}^{-2} \mathrm{~s}^{-1}$.

In Figure 5, highest erosion rate on wind turbine blade surface of glass fibre resin is plotted for different velocities and impingement angles. It is found that erosion rate elevates with increasing wind velocity for all angles. At low wind velocities, erosion rate is highest for $30^{\circ}$ impingement angle, which is followed by $90^{\circ}, 60^{\circ}, 45^{\circ}$ and $20^{\circ}$ angles respectively. However, erosion rate at high velocities for $90^{\circ}$ and $30^{\circ}$ angles are same. Exceptionally, at high velocities, erosion rate for $45^{\circ}$ angle is higher than $60^{\circ}$ impingement angle. At $65 \mathrm{~ms}^{-1}$ wind velocity, erosion rate for $45^{\circ}$ angle is $8 \times 10^{-7} \mathrm{kgm}^{-2} \mathrm{~s}^{-1}$, while for $60^{\circ}$ angle it is $6 \times 10^{-7} \mathrm{kgm}^{-2} \mathrm{~s}^{-1}$. In Figure 6 , erosion rate for $30^{\circ}$ impingement angle is plotted for jute fibre composite and $30-70 \%$ glass fibre resin. It shows clearly that erosion rate on jute fibre composite blade is higher than glass fibre resin.

\subsubsection{Wall shear stress}

In Figure 7, development of shear stress on wind turbine blade surface is shown by contour plot. It is visible that shear stress is very high at the edge of the blade. Hence, the possible damage from wind flow may occur at the blade edge. Similar to erosion rate, shear stress on the blade surface also elevates with increasing wind velocity for all angles, which is observed in Figure 8. Wall shear stress for $20^{\circ}$ impingement angle is much higher than other angles. Exceptionally, wall shear stress for $90^{\circ}$ angle at $65 \mathrm{~ms}^{-1}$ wind velocity is higher than $30^{\circ}$ and $60^{\circ}$ angles. However, at other velocities, shear stresses for $30^{\circ}$ and $60^{\circ}$ angles are found higher than $90^{\circ}$ angle. At $40 \mathrm{~ms}^{-1}$ wind velocity, shear stress for $60^{\circ}$ impingement angle is about $50 \mathrm{~Pa}$ which is much higher than $30^{\circ}$ angle. However, at higher velocities, shear stresses for $30^{\circ}$ and $60^{\circ}$ angles are found almost same. Lowest shear stress is developed for $45^{\circ}$ angle at all velocities. Shear stress is also higher on jute fibre composite blade than glass fibre resin as shown in Figure 9.

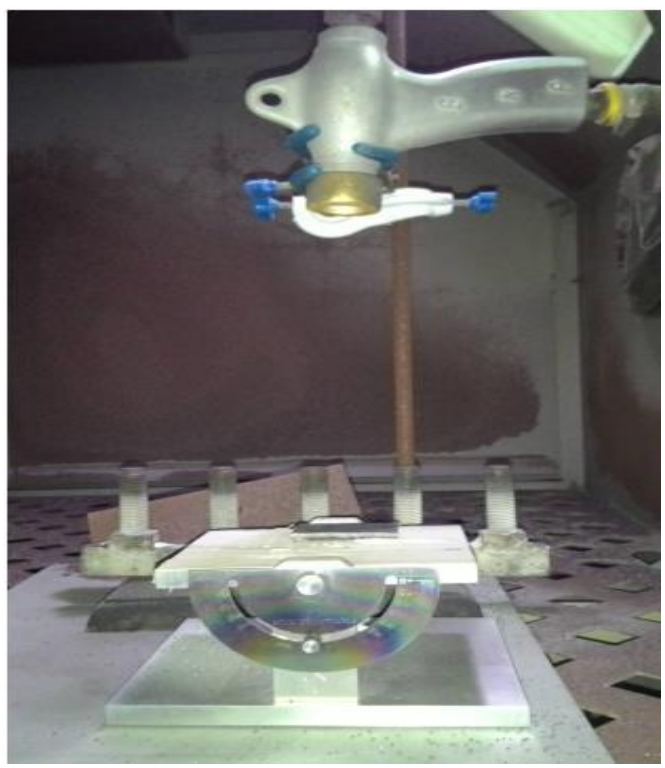

Figure 3: Test facility for sand blasting on wind turbine blade prototype 


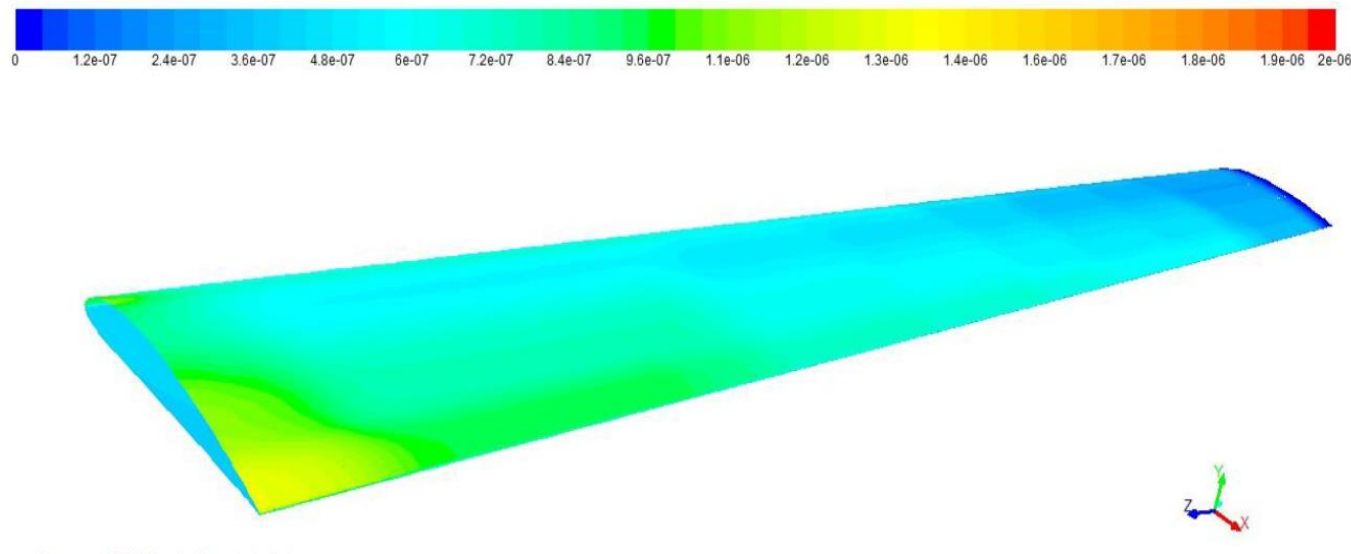

Contours of DPM Erosion Rate (kg/m2-s)

Figure 4: Erosion on wind turbine blade surface of glass fibre-resin for $60 \mathrm{~ms}^{-1}$ wind velocity and $90^{\circ}$ impingement angle

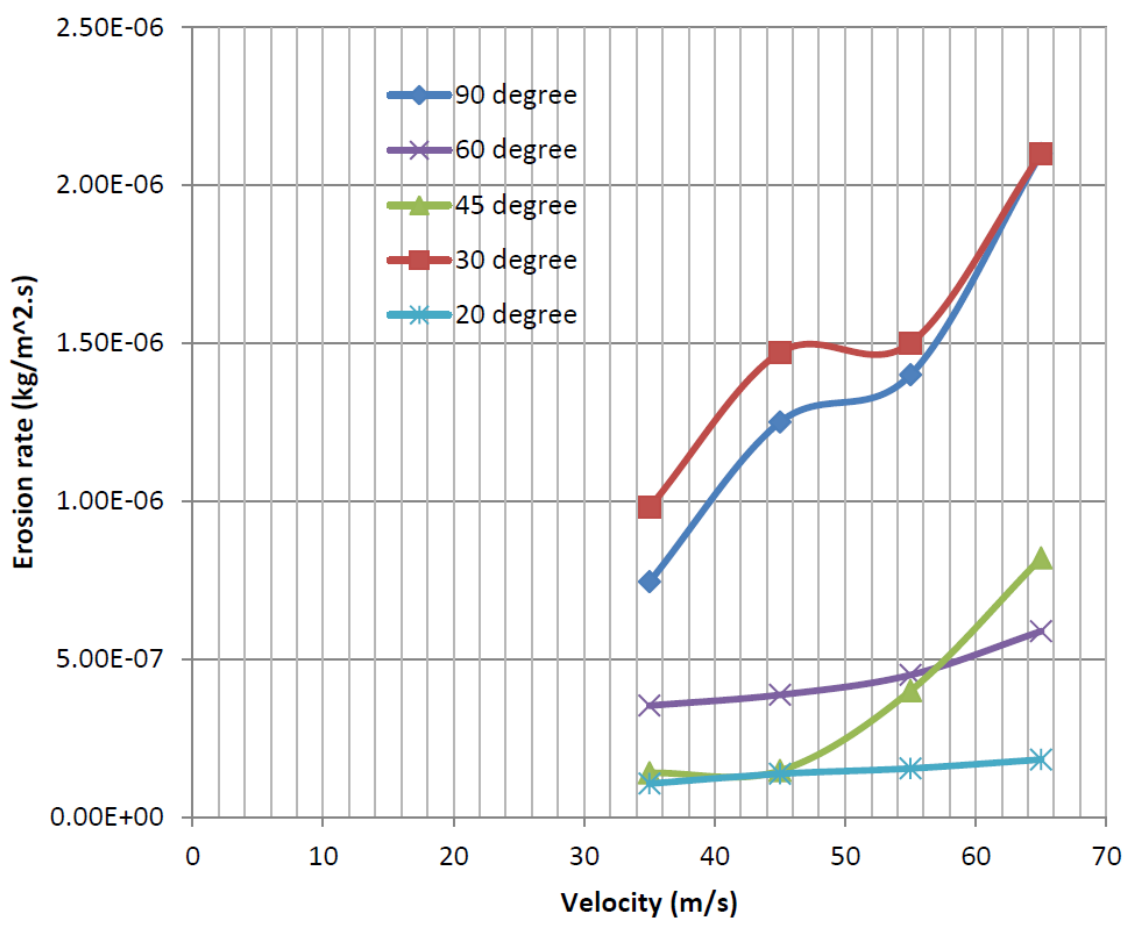

Figure 5: Erosion rate vs. wind velocity curve for glass fibre resin at different angle of attacks 


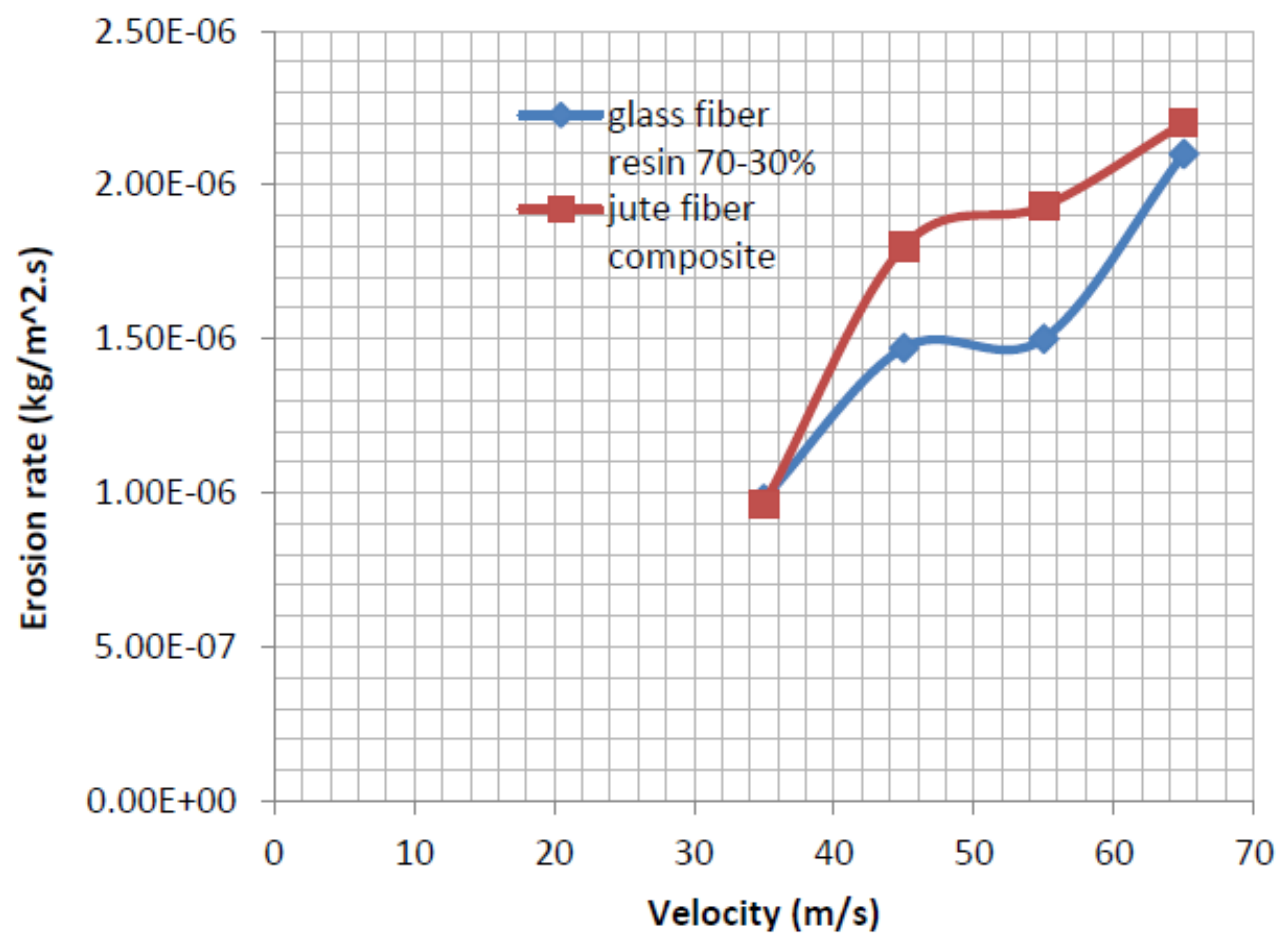

Figure 6: Rate of erosion on two different composite materials for $30^{\circ}$ angle of attack
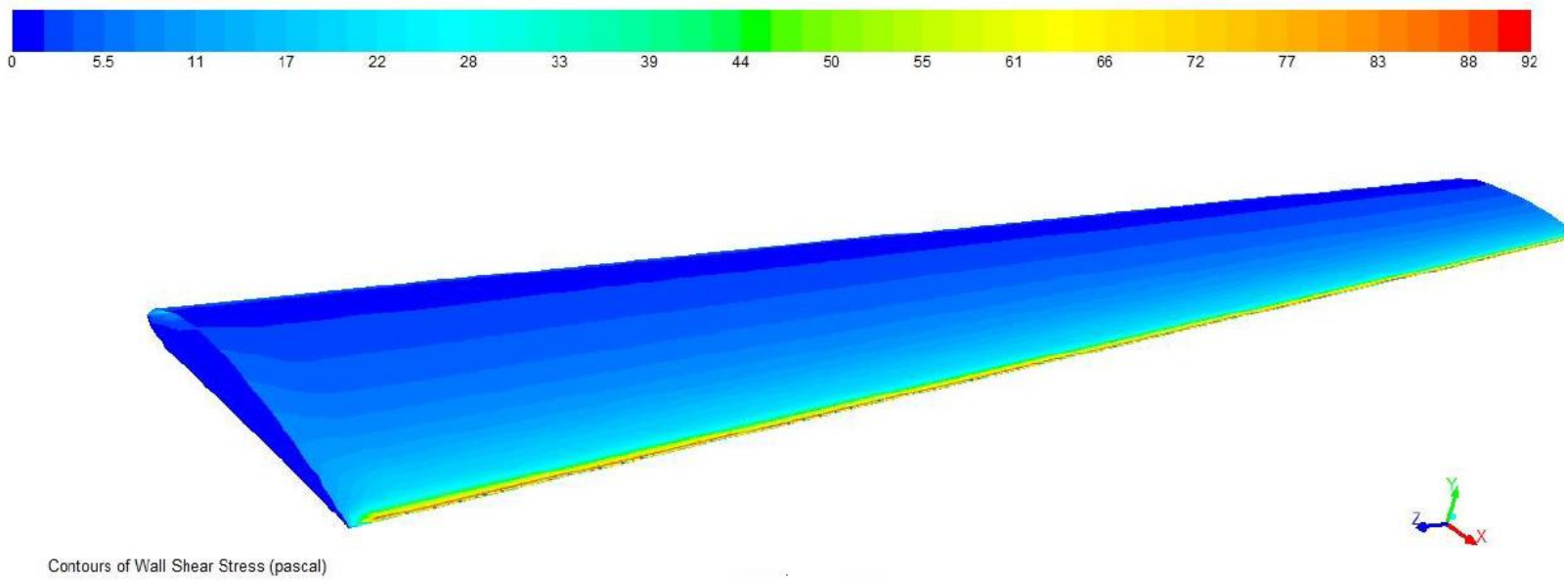

Figure 7: Shear stress on wind turbine blade surface of glass fibre-resin for $65 \mathrm{~ms}^{-1}$ wind velocity and sand injection from $90^{\circ}$ angle 


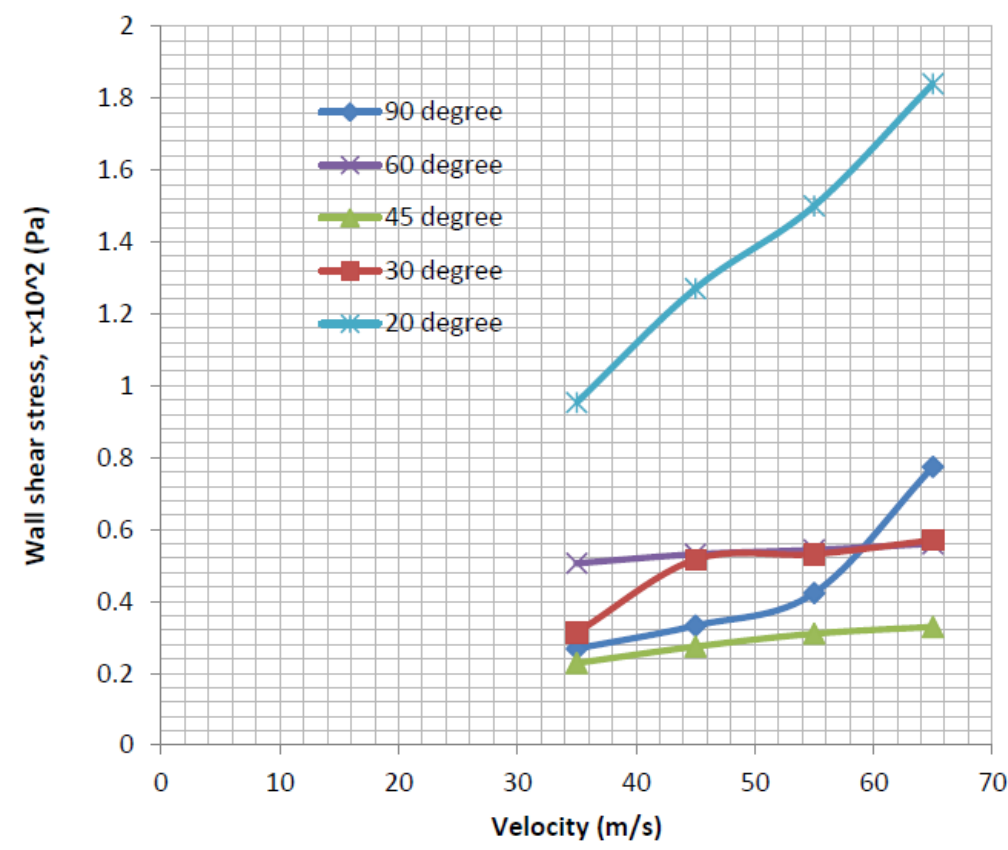

Figure 8: Wall shear stress vs. wind velocity curve for glass fibre resin at different angle of attacks

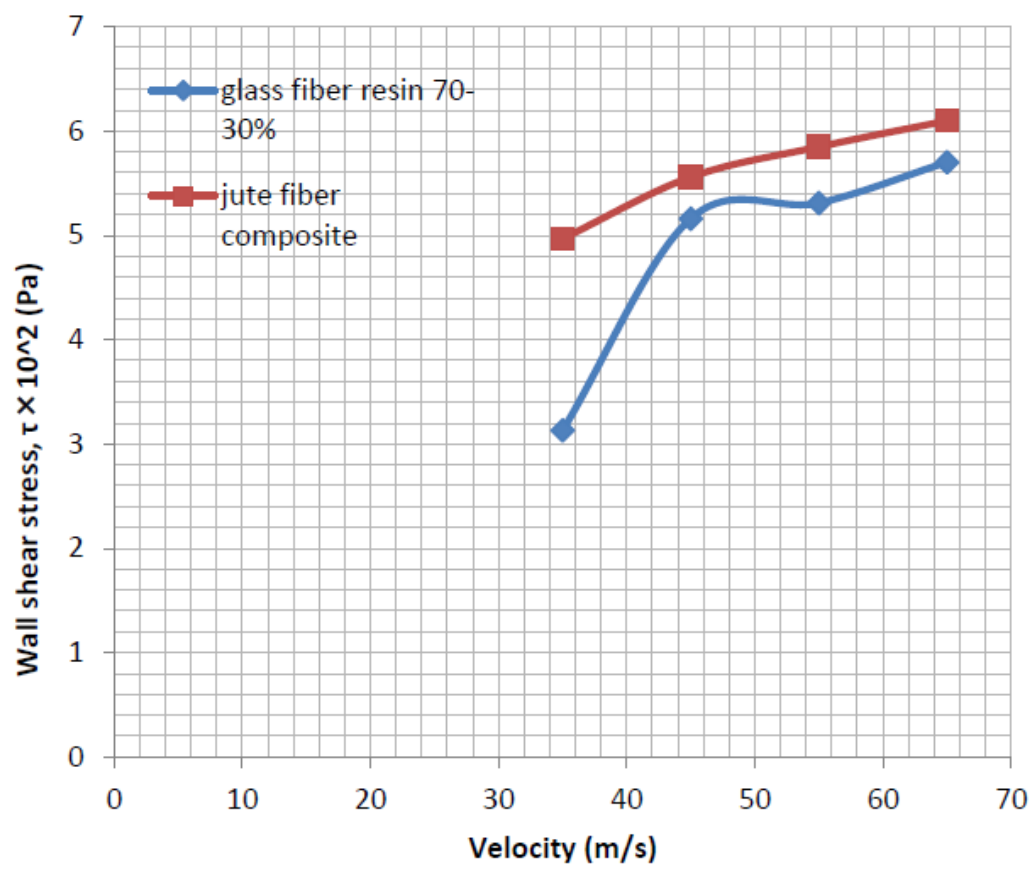

Figure 9: Development of shear stress on two different composite materials for $30^{\circ}$ angle of attack

\subsubsection{Strain rate}

In Figure 10, alike wall shear stress, strain rate is also high at the edge of the blade. Again, from Figure 11, it is seen that strain rate rises with the increment of wind velocity. Strain rate is found highest for $60^{\circ}$ angle of attack at all velocities, which is followed by $30^{\circ}, 20^{\circ}, 45^{\circ}$ and $90^{\circ}$ angles respectively. However, at $65 \mathrm{~ms}^{-1}$ wind velocity, same strain rate is observed for $45^{\circ}$ and $90^{\circ}$ angles. 


\subsubsection{Pressure distribution}

In Figure 12, pressure distribution on $30-70 \%$ glass fibre resin blade surface are shown for various angle of attacks has been plotted. It is perceived that highest pressure developed on blade surface declines with increasing angle. However, for $90^{\circ}$ angle of attack, highest pressure developed on the blade suddenly rises to $29.5 \mathrm{KPa}$, which is larger than pressures developed at all other angles.

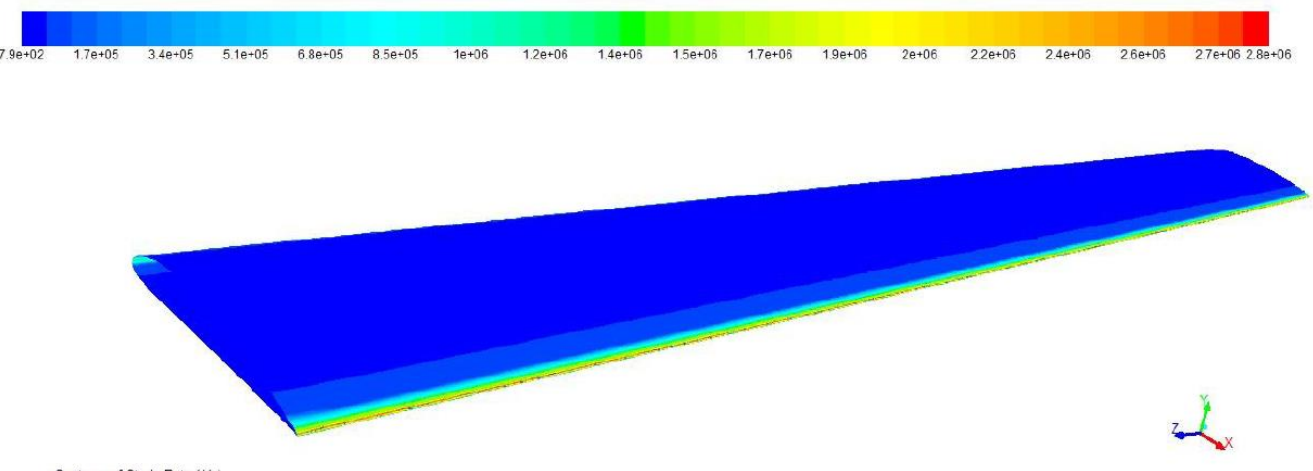

Figure 10: Strain rate on wind turbine blade surface of glass fibre-resin for $65 \mathrm{~ms}^{-1}$ wind velocity and sand injection from $60^{\circ}$ angle

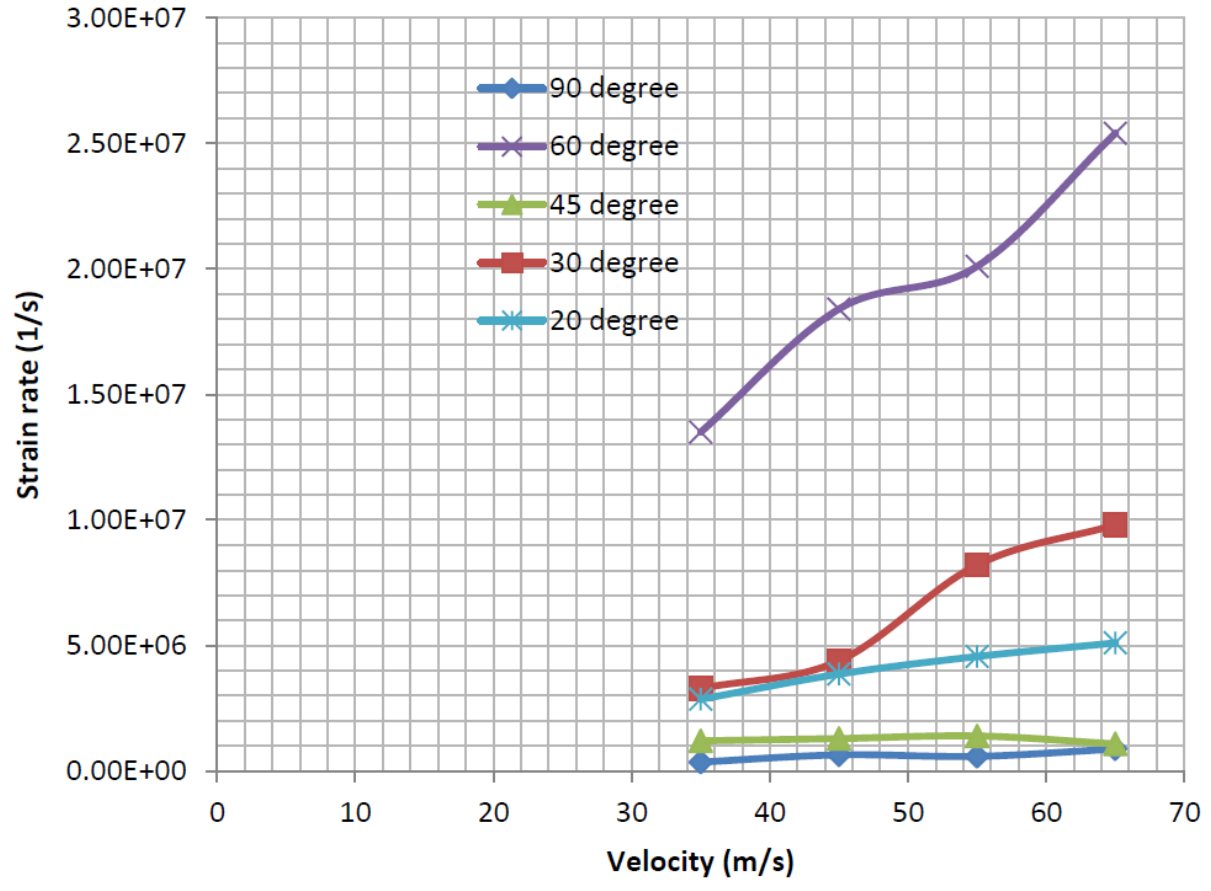

Figure 11: Strain rate vs. wind velocity curve for glass fibre resin 


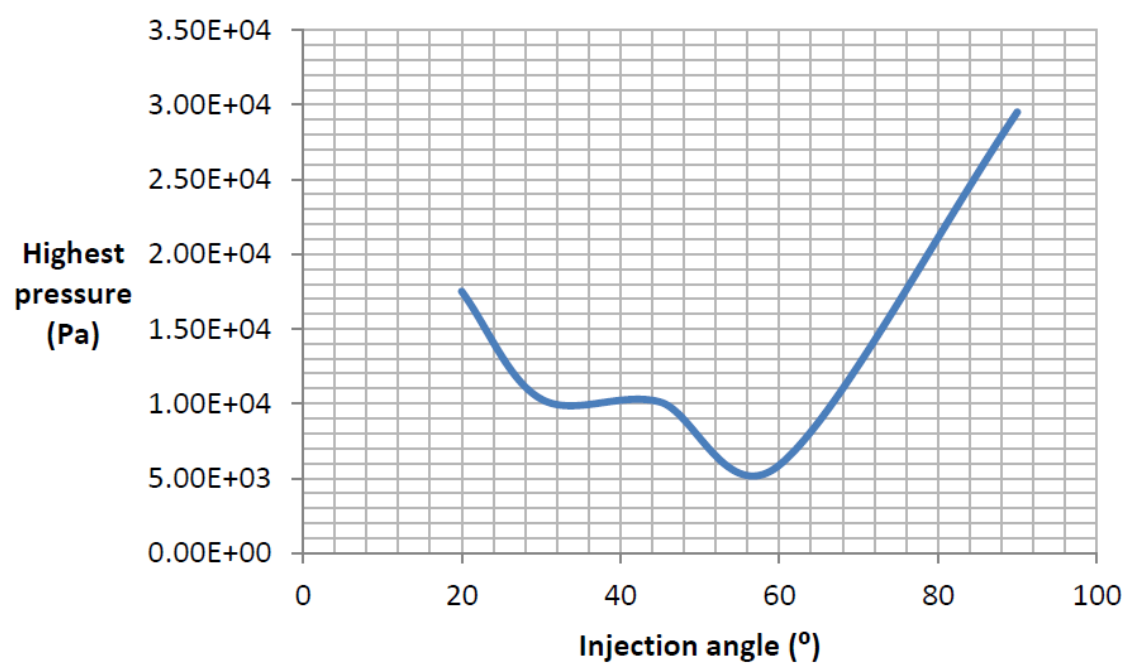

Figure 12: Highest pressure vs. injection angle curve for glass fibre resin, $35 \mathrm{~ms}^{-1}$ wind velocity, $0.3 \mathrm{~mm}$ diameter sand particle injection at $0.5 \mathrm{kgs}^{-1}$ mass flow rate.

\subsection{Experimental results}

5.2.1 Comparison with simulation results

In Figure 13, both experimental and simulation results of erosion rate for $5^{\circ}, 30^{\circ}$ and $60^{\circ}$ impingement angles have been plotted. Simulation results show good agreement with experimental data for $5^{\circ}$ and $60^{\circ}$ angles. However, for $30^{\circ}$ angle, erosion rate is observed higher in experiment. The mean absolute error (MAE) is defined using following equation:

$$
M A E=\frac{1}{M} \sum \frac{\mid R_{\text {erosion, }, \text { red }^{-} R_{\text {erosion, }, \exp } \mid}}{R_{\text {erosion, } \exp }} \times 100 \%
$$

Here, $M$ represents number of data points. Calculated MAE for $30^{\circ}$ impingement angle is $5.56 \%$.

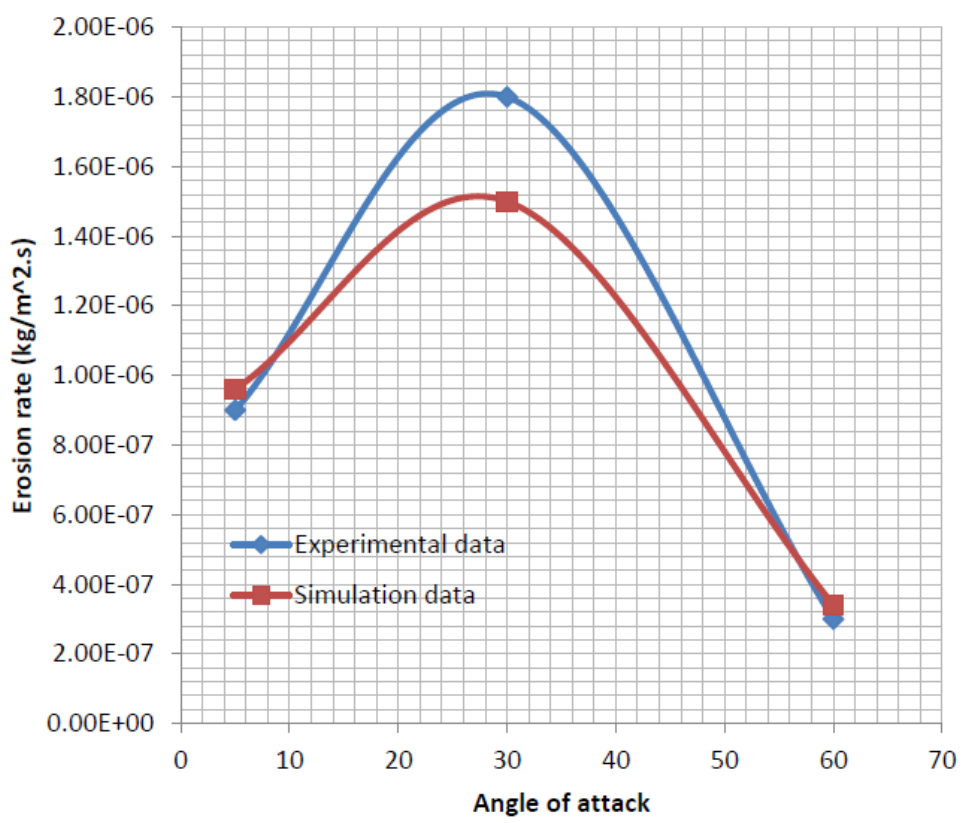

Figure 13: Comparison of experimental and simulation results for erosion rate at different angle of attacks 


\subsubsection{Surface roughness}

Surface roughness increases almost linearly with increasing impingement angle, which can be apprehended from Figure 14. Surface roughness on uncoated blade surface collided with 0.3-0.69 mm diameter particles is highest, which is expected. Surface roughness is found low for finer particle sizes.

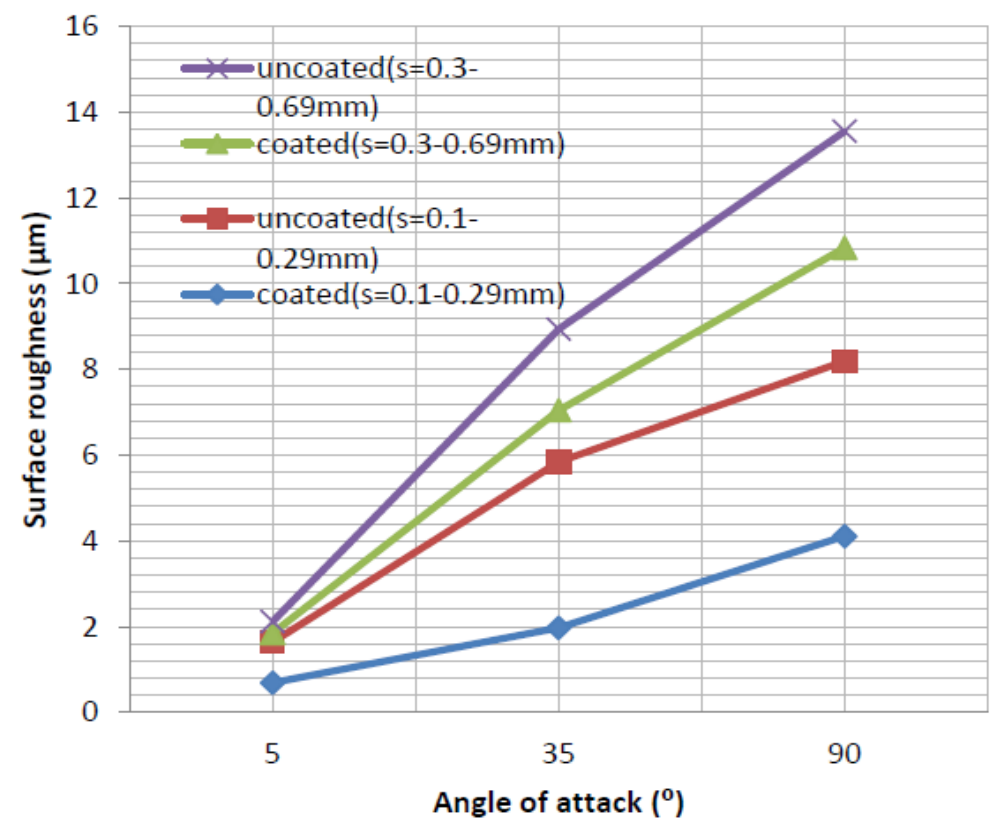

Figure 14: Experimental results of surface roughness vs. angle of attacks for different coated and uncoated surfaces

\section{Conclusions}

Rate of Erosion, development of shear stress and strain rate on wind turbine blade surface in desert conditions have been explored. Pressure distribution on wind turbine blade for various injection angles has also been observed. Major findings from numerical and experimental investigations are following:

1. In both simulation and experiment, erosion rate from wind turbine blade surface is found highest for $30^{\circ}$ impingement angle.

2. Shear stress development on wind turbine blade surface is highest for $20^{\circ}$ angle and lowest for $45^{\circ}$ angle. Although strain rate has been found lowest for $90^{\circ}$ impingement angle, it is also very low for $45^{\circ}$ angle.

3. Erosion rate on glass fibre resin has been found lower than jute fibre composite. Hence, it is more suitable as a wind turbine blade material from erosion perspective.

4. Pressure distribution on turbine blade surface is highest for $90^{\circ}$ angle of attack.

5. Surface roughness increases linearly with increment of impingement angle. As expected, surface roughness observed on uncoated blade surface is higher than coated surfaces.

\section{ACKNOWLEDGEMENT}

This research was funded by Ministry of Higher Education, Malaysia under Research Grant FRGS 14-131-0372. The authors are grateful to those who contributed directly and indirectly in producing this paper.

\section{References}

1. Mishnaevsky, L., Freere, P., Sinha, R., Acharya, P., Shrestha, R., \& Manandhar, P. (2011). Small wind turbines with timber blades for developing countries: Materials choice, development, installation and experiences. Renewable Energy, 36(8), 2128-2138.

2. Stachowiak, G.W. and Batchelor, A.W. 2001. Engineering Tribology, 2nd, Boston: Butterworth-Heinemann. 
3. Friedrich, K. 1997. Wear Performance of High Temperature Polymers and their Composites. CRC Press, : 221246.

4. Briscoe, B.J. 1993. The tribology of composite materials: a preface. Adv. Compos. Tribol, 8: 3-15.

5. Hager, A.M. and Davies, M. 1993. Short-fibre reinforced, high temperature resistant polymers for a wide field of tribological applications. Adv. Compos. Tribol, 8: 107-157.

6. Kong, C., Bang, J., \& Sugiyama, Y. (2005). Structural investigation of composite wind turbine blade considering various load cases and fatigue life. Energy, 30(11), 2101-2114.

7. Joosse, P. A., Van Delft, D. R. V., Kensche, C., Hahn, F., Jacobsen, T., \& van den Berg, R. (2000, January). Economic Use of Carbon Fibres in Large Wind Turbine Blades. In Proceedings of AIAA/ASME Wind Energy Symposium. Reno, NV.

8. Bahadur, S. and Gong, D. 1992. The role of copper compounds as fillers in the transfer and wear behavior of polyetheretherketone. Wear, 154: 151-165.

9. Schwartz, C.J. and Bahadur, S. 2001. The role of filler deformability, filler polymer bonding, and counterface material on the tribological behavior of polyphenylene sulfide (PPS). Wear, 251: 1532-1540.

10. Yu, L., Yang, S., Wang, H. and Xue, Q. 2000. An investigation of the friction and wear behaviors of micrometer copper particle-filled polyoxymethylene composites. J. Appl. Polymer Sci, 19: 2404-2410.

11. Bahadur, S. and Kapoor, A. 1992. The effect of $\mathrm{ZnF2,} \mathrm{ZnS}$ and PbS fillers on the tribological behavior of nylon 11. Wear, 155: 49-61.

12. A. Patnaik, T. G. Mamatha, S. Biswas, \& P. Kumar, (2012). Damage assessment of titania filled zinc-aluminum alloy metal matrix composites in erosive environment: A comparative study. Materials \& Design, 36 (2012), 511521.

13. Drensky, G., Hamed, A., Tabakoff, W., \& Abot, J. (2011). Experimental investigation of polymer matrix reinforced composite erosion characteristics. Wear, 270(3), 146-151.

14. Fiore, G., \& Selig, M. S. A Simulation of Operational Damage for Wind Turbine Blades.

15. N. Gaudern, A practical study of the aerodynamic impact of wind turbine blade leading edge erosion. Journal of Physics: Conference Series, 524(1) (2014).

16. A. A. Hamed, W. Tabakoff, R. B. Rivir, K. Das \& P. Arora. Turbine blade surface deterioration by erosion. Journal of Turbomachinery, 127(3) (2005), 445-452.

17. Foley, T., \& Levy, A. (1983). The erosion of heat-treated steels. Wear, 91(1), 45-64.

18. Hutchings, I. M. (1992). Tribology: friction and wear of engineering materials.

19. Rodríguez, E., Flores, M., Pérez, A., Mercado-Solis, R. D., González, R., Rodríguez, J., \& Valtierra, S. (2009). Erosive wear by silica sand on AISI H13 and 4140 steels. Wear, 267(11), 2109-2115.

20. Rico, A., Poza, P., \& Rodríguez, J. (2013). High temperature tribological behavior of nanostructured and conventional plasma sprayed alumina-titania coatings. Vacuum, 88, 149-154.

21. Liang, F., Gou, J., Kapat, J., Gu, H., \& Song, G. (2011). Multifunctional nanocomposite coating for wind turbine blades. International Journal of Smart and Nano Materials, 2(3), 120-133.

22. Zhang, H., Tang, L., Zhang, Z., Gu, L., Xu, Y., \& Eger, C. (2010). Wear-resistant and transparent acrylate-based coating with highly filled nanosilica particles. Tribology International, 43(1), 83-91.

23. B. E. Launder and D. B. Spalding. Lectures in Mathematical Models of Turbulence. Academic Press, London, England. 1972.

24. S. V. Patankar and D. B. Spalding, A calculation procedure for heat, mass and momentum transfer in threedimensional parabolic flows. International Journal of Heat and Mass Transfer, 15(10) (1972), 1787-1806. 